\title{
The use of ketamine for perioperative pain management
}

\author{
Soo Kyung Lee \\ Department of Anesthesiology and Pain Medicine, Hallym University College of Medicine, Anyang, Korea
}

Ketamine is a phencyclidine derivative that was introduced into clinical use in 1965. It is a noncompetitive N-methyl-Daspartate (NMDA) receptor antagonist, and has analgesic and antihyperalgesic properties. Today, it is unusual to use ketamine as the first-line drug in general anesthesia and the role of ketamine is changing in clinical practice.

Ketamine may be a useful adjunct to improve the management of perioperative pain, because the mechanism of action differs from that of opioids. The antihyperalgesic mechanism of ketamine is not fully understood. Opioid-induced hyperalgesia may be associated with the influence of excitatory neurotransmission [1]. Therefore, ketamine can prevent the development of tolerance and hyperalgesia by inhibition of the NMDA receptors [2,3].

Various studies have reported on the potentiation of opioidinduced analgesia and the opioid-sparing effect of ketamine [4-6]. However, the results from several clinical trials are controversial. A subanesthetic dose, intravenous intraoperative ketamine reduced mechanical hyperalgesia and improved postoperative analgesia [7], and a small dose of ketamine given before skin incision decreased postoperative pain and reduced morphine consumption after open renal surgery [8]. A small intravenous dose of ketamine before the first incision followed by a 24-h infusion had a morphine-sparing effect after total hip arthroplasty and decreased postoperative chronic pain up to 6 months after surgery [9].

Intravenous patient-controlled analgesia (PCA) with a subanesthetic ketamine and morphine following transthoracic lung and heart surgery resulted in lower pain scores, reduced morphine consumption and shorter postoperative IV-PCA dependence, associated with cardiovascular stability and better respiratory parameters [10]. The potentiation of opioid-induced analgesia and the opioid-sparing effect of ketamine were observed in pediatric patients $[6,11]$.

In this issue of the Korean Journal of Anesthesiology [12], the authors assessed the effectiveness of ketamine, when given intravenously via a PCA pump, as an alternative to nonsteroidal anti-inflammatory drugs towards the management of acute postoperative pain. The authors concluded that a small dose of ketamine $(0.5-2.5 \mu \mathrm{g} / \mathrm{kg} / \mathrm{min})$ proportional to fentanyl was not only safe, but also lowered postoperative pain intensity in patients undergoing spinal fusion; however, the opioidsparing effects of ketamine were not demonstrated.

However, there was no benefit provided to patients with either small-dose ketamine combined with morphine for PCA after major orthopedic surgery [13] or the addition of a low dose of ketamine to a multimodal analgesic regimen after gynecolo gical surgery [14].

Because of their side effects, low doses of ketamine can be administered in clinical practice. Even subtherapeutic doses of ketamine can cause hallucinogenic effects. In a previous study, PCA with morphine and ketamine, in a dose ratio of $1: 1$, was safe and effective. However, it was infrequently a reason for discontinuing the regimen owing to side-effects [15]. Low-dose ketamine is defined as a bolus dose of less than $2 \mathrm{mg} / \mathrm{kg}$ when given intramuscularly, or less than $1 \mathrm{mg} / \mathrm{kg}$ when administered via the intravenous or epidural route, and an intravenous infusion rate of $\leq 20 \mu \mathrm{g} / \mathrm{kg} / \mathrm{min}$ [16].

The developing rhesus macaque brain was sensitive to the apoptotic action of ketamine at both a fetal and neonatal age, and exposure duration of $5 \mathrm{~h}$ was sufficient to induce a significant neuroapoptotic response [17]. Therefore, it is

Corresponding author: Soo Kyung Lee, M.D., Department of Anesthesiology and Pain Medicine, Hallym University Sacred Heart Hospital, 896, Pyeongchon-dong, Dongan-gu, Anyang 431-070, Korea. Tel: 82-31-380-3945, Fax: 82-31-385-3244, E-mail: agnetask@yahoo.co.kr (c) This is an open-access article distributed under the terms of the Creative Commons Attribution Non-Commercial License (http:// creativecommons.org/licenses/by-nc/3.0/), which permits unrestricted non-commercial use, distribution, and reproduction in any medium, provided the original work is properly cited. 
necessary to keep the potential neuroapoptotic effect of ketamine in mind, during organogenesis $[17,18]$.

Ketamine was previously only available as a racemic mixture of two enantiomers. The $\mathrm{S}(+)$ isomer has increased anesthetic potency and decreased psychotomimetic side effects; it has become available in some countries. Recently, Suppa et al. [19] reported that preventive S-ketamine, administered by an intramuscular bolus after birth and continuous intravenous infusion, enhanced the analgesic effect of morphine even after ketamine effect had ceased, suggesting anti-hyperalgesic action of the drug.

Low doses of ketamine may be considered as a useful and safe adjunct in perioperative pain management, according to the patient's conditions and type of surgery. Ketamine displays antihyperalgesic and analgesic effects, and has no major dysphoric adverse effects at low doses. When used correctly, ketamine is an inexpensive and versatile drug.

\section{References}

1. Angst M, Clark DJ. Opioid-induced hyperalgesia: a qualitative systematic review. Anesthesiology 2006; 104: 570-87.

2. Rivat C, Laulin JP, Corcuff JB, Célèrier E, Pain L, Simonnet G. Fentanyl enhancement of carrageenan-induced long-lasting hyperalgesia in rats: prevention by the N-methyl-D-aspartate receptor antagonist ketamine. Anesthesiology 2002; 96: 381-91.

3. Laulin JP, Maurette P, Corcuff JB, Rivat C, Chauvin M, Simonnet G. The role of ketamine in preventing fentanyl-induced hyperalgesia and subsequent acute morphine tolerance. Anesth Analg 2002; 94: 1263-9.

4. Carstensen M, Møller AM. Adding ketamine to morphine for intravenous patient-controlled analgesia for acute postoperative pain: a qualitative review of randomized trials. Br J Anaesth 2010; 104: 4016.

5. Bell RF, Dahl JB, Moore RA, Kalso E. Peri-operative ketamine for acute post-operative pain: a quantitative and qualitative systematic review (Cochrane review). Acta Anaesthesiol scand 2005; 49: 140528.

6. Dahmani S, Michelet D, Abback PS, Wood C, Brasher C, Novoche $\mathrm{Y}$, et al. Ketamine for perioperative pain management in children: a meta-analysis of published studies. Pediatr Anaesth 2011; 21: 636-52.

7. De Kock M, Lavand'homme P, Waterloos H. 'Balanced analgesia' in the perioperative period: is there a place for ketamine? Pain 2001;
92: 373-80.

8. Parikh B, Maliwad J, Shah VR. Preventive analgesia: Effect of small dose of ketamine on morphine requirement after renal surgery. J Anaesthesiol Clin Pharmacol 2011; 27: 485-8.

9. Remérand F, Le Tender C, Baud A, Couvret C, Pourrat X, Favard L, et al. The early and delayed analgesic effects of ketamine after total hip arthroplasty: a prospective, randomized, controlled, doubleblind study. Anesth Analg 2009; 109: 1963-71.

10. Nesher N, Serovian I, Marouani N, Chazan S, Weinbroum AA. Ketamine spares morphine consumption after transthoracic lung and heart surgery without adverse hemodynamic effects. Pharmacol Res 2008; 58: 38-44.

11. Min TJ, Kim WY, Jeong WJ, Choi JH, Lee YS, Kim JH, et al. Effect of ketamine on intravenous patient-controlled analgesia using hydromorphone and ketorolac after the Nuss surgery in pediatric patiets. Korean J Anesthesiol 2012; 62: 142-7.

12. Yeom JH, Chon MS, Jeon WJ, Shim JH. Peri-operative ketamine with the ambulatory elastometric infusion pump as an adjuvant to manage acute postoperative pain after spinal fusion in adults: a prospective randomized trial. Korean J Anesthesiol 2012; 63: 54-8.

13. Sveticic G, Farzanegan F, Zmoos P, Zmoos S, Eichenberger U, Curatolo M. Is the combination of morphine with ketamine better than morphine alone for postoperative intravenous patientcontrolled analgesia? Anesth Analg 2008; 106: 287-93.

14. Aubrun F, Gaillat C, Rosenthal D, Dupuis M, Mottet P, Marchetti F, et al. Effect of a low-dose ketamine regimen on pain, mood, cognitive function and memory after major gynaecological surgery: a randomized, double-blind, placebo-controlled trial. Eur J Anaesthesiol 2008; 25: 97-105.

15. Sveticic G, Eichenberger U, Curatolo M. Safety of mixture of morphine with ketamine for postoperative patient-controlled analgesia: an audit with 1026 patients. Acta Anaesthesiol Scand 2005; 49: 870-5.

16. Schmid RL, Sandler AN, Katz J. Use and efficacy of low-dose ketamine in the management of acute postoperative pain: a review of current techniques and outcomes. Pain 1999; 82: 111-25.

17. Brambrink AM, Evers AS, Avidan MS, Faber NB, Smith DJ, Martin LD, et al. Ketamine-induced neuroapoptosis in the fetal and neonatal rhesus macaque brain. Anesthesiology 2012; 116: 372-84.

18. Lois F, De Kock M. Something new about ketamine for pediatric anesthesia? Curr Opin Anaesthesiol 2008; 21: 340-4.

19. Suppa E, Valente A, Caratci S, Zanfini BA, Draisci G. A study of low-dose S-ketamine infusion as "preventive" pain treatment for cesarean section with spinal anesthesia: benefits and side effects. Minerva Anesthesiol 2012; 78: 774-81. 